\title{
Flat Squamous Papilloma in Esophagus A Complication Associated with Gerd? About A Case
}

ISSN: 2637-7632

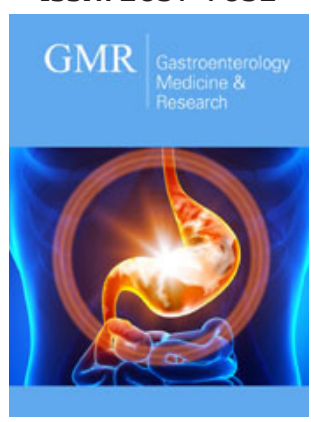

*Corresponding author: Guillermo Hernández, Specialist in General Surgery and highly specialized in gastrointestinal endoscopy, Private sector, Torre Medica GP, Toluca, State of Mexico, Mexico

Submission: 侮 June 13, 2020

Published: 笽December 14, 2021

Volume 6 - Issue 3

How to cite this article: Guillermo Hernández. Flat Squamous Papilloma in Esophagus A Complication Associated with Gerd? About A Case. Gastro Med Res. 6(3). GMR. 000639. 2021.

DOI: 10.31031/GMR.2021.06.000639

Copyright@ Guillermo Hernández, This article is distributed under the terms of the Creative Commons Attribution 4.0 International License, which permits unrestricted use and redistribution provided that the original author and source are credited.

\section{Guillermo Hernández*}

Specialist in General Surgery and highly specialized in gastrointestinal endoscopy, Private sector, Torre Medica GP, Toluca, State of Mexico, Mexico

\section{Introduction}

The clinical case of a 25-year-old male patient is presented, with a history of abundant intake of spicy 3-4 times a week, intake of alcoholic beverages 8 ounces on average per week he comes to a medical consultation for presenting heartburn and regurgitation of 3 months of evolution he had been treated by a family doctor with omeprazole, metoclopramide and trimebutine $200 \mathrm{mg}$, without improvement, in the last two weeks low dysphagia was added to solid food, reason for consulting a specialist doctor. He is instructed to perform panendoscopy with biopsy, which reports grade "C" esophagitis, exophytic lesion with smooth edges, pale pink, well delimited around $1.5 \mathrm{~cm}$ long linear erosion, soft consistency (Figure 1) and smooth after taking biopsies, located in the lower third of the esophagus, as well as follicular gastropathy located in the antrum, biopsies were also taken from this area in separate vials; the histopathological report of the biopsies of the esophageal lesion in the microscopic description mentions papillary projections with fibrovascular axes covered by nonkeratinized stratified flat epithelium with areas of erosion and recent hemorrhage, (Figure 2) concluding flat squamous papilloma, chronic esophagitis due to grade reflux II, without evidence of dysplastic changes and/or Barrett. Gastric biopsies reported chronic gastritis of the follicular variety with moderate activity associated with infection by Helicobacter pylori bacilli in moderate quantity. After panendoscopy, he was prescribed levopantoprazole $20 \mathrm{mg}$ twice a day for 8 weeks, hygienic dietary measures for gastroesophageal reflux disease, with good response to symptoms, control endoscopy was performed at 12 weeks with endoscopic improvement of the lesion (Figure 3).

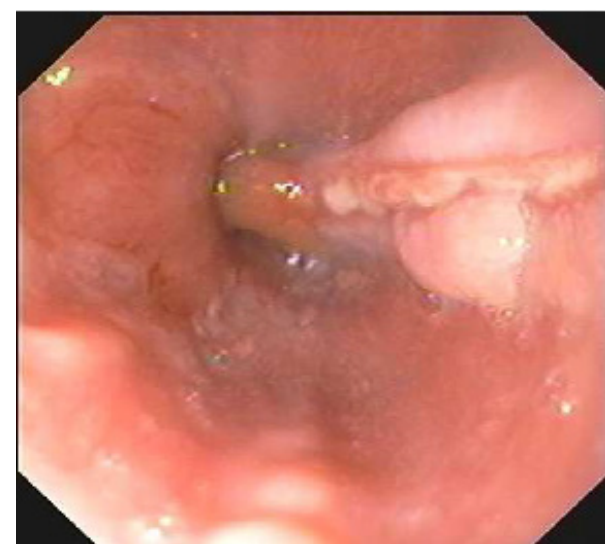

Figure 1: Distal esophageal third showing grade "C" erosive esophagitis surrounded by elevated mucosa, smooth edges, pink discoloration that, upon biopsy, has a soft consistency. 


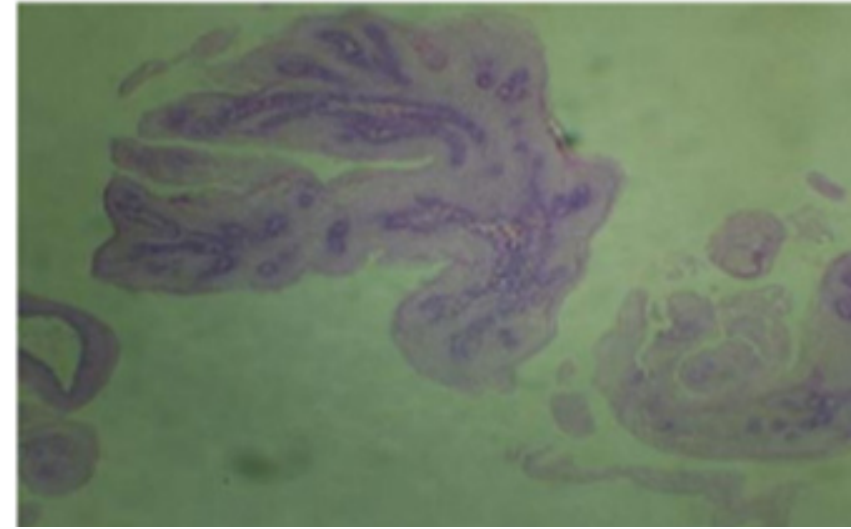

Figure 2: Papillary views with fibrovascular axes lined by nonkeratinized stratified flat epithelium.

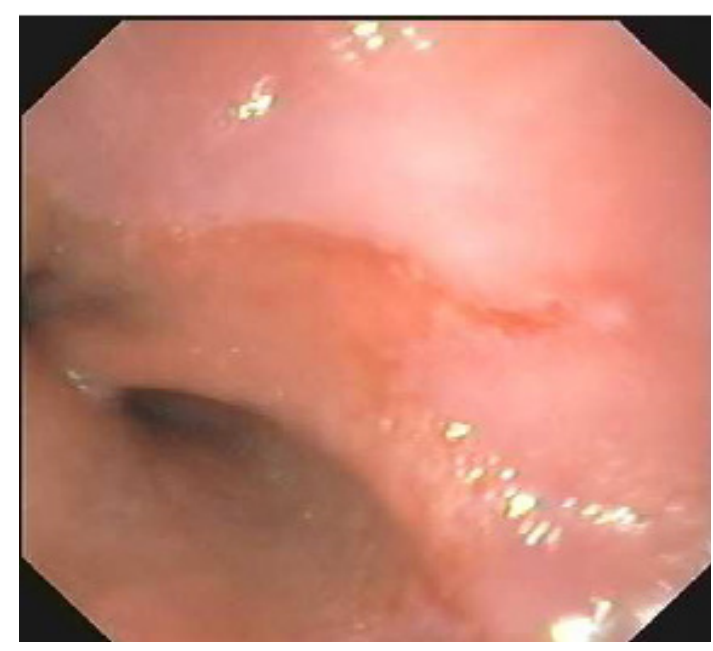

Figure 3: Control endoscopy at 12 weeks. Shows mild grade "A" esophagitis.

\section{Discussion}

Squamous papilloma of the esophagus is a rare pathology with a prevalence of $0.07 \%$ [1], it could be associated with infection by human papilloma virus, however, it is frequently associated with reflux or irritation of the esophageal mucosa, generally located in the middle or lower third [2] It is part of the benign tumors of the esophagus, in the sub-classification of epithelial tumors which of $50-60 \%$ are discovered incidentally, in the course of an endoscopy indicated for very different reasons, squamous papilloma is the tumor lesion Benign esophageal more frequent, in general they are small, sessile or semi-pediculated, located, usually in the lower esophageal third and rarely in the middle third, their etiopathogenesis is unknown, it is not a precancerous lesion [3] In its etiology, 2 theories have been described mainly, mechanical or chemical irritation of the mucosa due to chronic gastroesophageal reflux with subsequent development of epithelial lesion and the second, associated with human papillomavirus, especially viral types 16 and 18, its transmission route is directly, associated with risky sexual practices [4], but a relationship of these practices in the development of esophageal papillomas has not yet been established. [5] At the time of diagnosis, it would have been interesting to perform immunohistochemistry or PCR to detect human papillomavirus infection; however, the patient did not perform them, although the patient had no risk factors for acquiring human papillomavirus (high-risk sexual practices). The good response in relation to the patient's symptoms, in addition to the control endoscopic image at 12 weeks that shows improvement, practically confirm that the etiology was local irritation secondary to acid reflux [6].

\section{Conclusion}

Squamous esophageal papilloma is a rare complication associated with chemical irritation secondary to gastroesophageal reflux, it should be considered to rule out human papillomavirus infection by analyzing the patient's history and local infrastructure. It is a non-serious condition generally detected incidentally in endoscopy studies.

\section{Conflict of Interest}

The author declares that he has no conflict of interest.

\section{References}

1. Grube-Pagola P, Ruiz-Juárez I, Remes Troche JM (2011) Squamous papilloma of the esophagus: rare endoscopic finding. Journal of Gastroenterology of Mexico 76: 249-250.

2. Vázquez-Iglesias JL (2009) Diagnostic and therapeutic digestive endoscopy. Ed Medica Panamericana, pp. 431-432.

3. Pineda-Oliva OJ (2015) Squamous papilloma of the esophagus: Report of 31 cases in a tertiary hospital. Endoscopy 27:

4. Bonh O, Navarro L (2008) Identification of human papillomavirus in esophageal squamous papilomas. World J Gastroenterol 14: 7107-7111.

5. Barbaglia Y, Jiménez F, Tedeschi F (2013) Esophageal papilloma: Description of a case, molecular identification of human papillomavirus and review of the literature. Acta Gastroenterol Latinoam 43(3): 231234.

6. Politoske EJ (1992) Squamous papilloma of the esophagus associated with the human papillomavirus. Gastroenterology 102(2): 668-673. 